\title{
Avaliação biométrica de caracteres do melão de São Caetano (Momordica charantia L)
}

ASSIS, J.P.**; SOUSA, R.P.1; LINHARES, P.C.F.1; PEREIRA, M.F.S.'; MOREIRA, J.C.1

1Universidade Federal Rural do Semi-Árido, Departamento de Ciências Vegetais, Campus Mossoró, Av. Francisco

Mota, Caixa Postal 137, 59625-900, RN-Brasil *Autor para correspondência: janilson@ufersa.edu.br

\begin{abstract}
RESUMO: O melão de São Caetano, planta trepadeira originaria do leste indiano e sul da Índia, é encontrada no bioma caatinga. Neste trabalho objetivou-se avaliar a biometria dos frutos e 0 número de sementes por fruto do melão de São Caetano. Os frutos foram coletados em área de vegetação nativa do campus da Universidade Federal Rural do Semi-Árido (UFERSA), situada no município de Mossoró, RN, seguindo para o laboratório de fitotecnia para a determinação das seguintes características: comprimento, diâmetro e peso dos frutos, bem como o número de sementes por fruto. As análises descritivas e gráficas foram realizadas utilizando o pacote estatístico software R-project. As variáveis, comprimento e diâmetro apresentaram baixa amplitude de variação e bons valores de coeficiente de variação. Já o peso do fruto e o número de sementes por fruto mostraram alta amplitude de variação. Verificou-se alto grau de simetria e distribuição mesocúrtica para todas as características avaliadas nesse estudo. Constatou-se também a correlação linear simples positiva significativa entre o comprimento e o diâmetro, e não significativa entre o peso e o número de sementes por fruto, e que os dados referentes a todas as características do fruto do melão de São Caetano avaliadas neste trabalho se ajustaram à distribuição normal de probabilidade, o que permite a realização de inferências com base estatística.
\end{abstract}

Palavras- chave: Momordica charantia L., espécie trepadeira, estatística descritiva, inferência.

ABSTRACT: Biometric evaluation of the characters of the melon from Sao Caetano (Momordica charantia L). The melon from Sao Caetano is a climbing plant, originally from India and South East India and is found in the savanna biome. This study aimed to evaluate the biometric fruit and the number of seeds per fruit of the melon Sao Caetano. The fruits were collected inside a native vegetation area of the campus at the Universidade Federal Rural do Semi-Árido (UFERSA), located in the city of Mossoró, RN. They were then taken to the laboratory of crop science, for the determination of the following characteristics: length, diameter and fruit weight as well as number of seeds per fruit. The descriptive and graphical analyzes were performed by using the statistical package $\mathrm{R}$-project software. The length and diameter variables exhibited a low amplitude variation and a good value for the coefficient of variation. However, the fruit weight and number of seeds per fruit showed a high amplitude variation. There was a high degree of symmetry and a flattened distribution for all traits evaluated in this study. It was also found significant positive simple linear correlation between the length and diameter, and no significant difference between the weight and number of seeds per fruit. The data related to all features of the São Caetano melon fruit evaluated in this study were adjusted to normal distribution of probability which allows the performance of interferences with statistical basis.

Keywords: Momordica charantia L., vine species, descriptive statistical, inference.

\section{INTRODUÇÃO}

O melão de São Caetano (Momordica charantia L.) é uma planta trepadeira, originária do leste indiano e sul da China, monóica com flores amarelas isoladas nas axilas das folhas (Robinson \& Decker - Walter, 1997). Todas as partes da planta, incluindo o fruto, possuem sabor amargo. $O$ fruto é oblongo, assemelha-se a um pepino pequeno, é verde quando imaturo e muda para uma tonalidade alaranjada quando maduro (Grover \& Yadav, 2004).

A medicina alternativa através da utilização das ervas medicinais permanece como uma das formas mais comuns de terapia disponíveis às 
populações de todo mundo. De acordo com a "World Health Organization", aproximadamente três quartos da população mundial usam atualmente ervas e outras formas de medicina tradicional para tratar das doenças (Rao et al., 2004). Em países em desenvolvimento $80 \%$ da população continua a usar a medicina tradicional para a solução dos problemas básicos de saúde. Na década passada, conseqüentemente, várias pesquisas enfocaram na avaliação científica de drogas tradicionais de plantas (Grover \& Yadav, 2004). Nos países orientais, situados em regiões tropicais e subtropicais, há muitos recursos herbais que são considerados como alimentos e como auxiliares nos tratamentos de saúde, e acredita-se que os hábitos de consumo destas ervas rendem inúmeros efeitos benéficos à saúde humana (Dubick, 1986).

Momordica charantia L. é uma espécie pertencente à família das cucurbitáceas, onde muitas espécies desta família são comestíveis e reúnem importante valor econômico no Brasil, especialmente aquelas dos gêneros Cucurbita, Momordica, Fevillea e Sechium (Di Stasi \& Hiruma Lima, 2002). Possui as seguintes sinonímias: Momordica chinensis, M. elegans, $M$. indica, $M$. operculata, M. sinensis, Sicyos fauriei. É uma espécie silvestre comumente encontrada em áreas urbanas e rurais, sendo conhecida e utilizada por suas propriedades medicinais (Ribeiro et al., 2004, Giron et al., 1991; Lans \& Brown, 1998), sendo tradicionalmente utilizada por países como Brasil, China, Colômbia, Cuba, Gana, Haiti, Índia, México, Malásia, Nova Zelândia, Nicarágua, Panamá e Peru (Grover \& Yadav, 2004).

O nome latin Momordica significa "mordida", referindo-se às bordas das folhas que parecem terem sido mordidas. É uma planta revolucionária pela sua versatilidade como alimento e em aplicações terapêuticas (Assubaie \& El-Garawany, 2004). A forma de erva daninha pode ter sido trazida junto com sementes de outras culturas e transformaramse em um problema em plantações por todo o mundo (Robinson \& Decker-Walters, 1997). É tolerante a um número variável de ambientes (Lim, 1998) e pode crescer em climas tropicais e subtropicais (Reyes et al., 1994).

O melão de São Caetano é uma planta daninha bastante freqüente em pomares, cafezais, sobre cercas e alambrados e em terrenos baldios. Ocorre virtualmente em todas as regiões habitadas do país (Lorenzi, 2000). As práticas culturais são similares ao do pepino (Reyes et al., 1994). O fruto imaturo do melão é valorizado pelo seu sabor amargo e geralmente é consumido fresco (inteiro ou em fatias), mas pode também ser feito como pickles, conservado em salmoura. São embalados em caixas com 5 quilogramas do produto e vendidos em Melbourne e em Sydney como uma planta medicinal, indicada para Inflamações hepáticas, diabetes, cólicas abdominais, problemas de pele, queimaduras com leucorréias purulentas, furúnculos e hemorróidas, triglicerídios, prisão de ventre, tosse, entre outras (Vinning, 1995).

A caracterização biométrica de frutos e sementes pode fornecer subsídios importantes para a diferenciação de espécies do mesmo gênero. Carpanezzi \& Marques (1981) evidenciaram que o peso das sementes de $\mathrm{H}$. courbaril é quase duas vezes superior ao peso das sementes de H. parvifolia. A biometria da semente também está relacionada a características da dispersão e do estabelecimento de plântulas (Fenner, 1993), sendo também utilizada para diferenciar espécies pioneiras e não pioneiras em florestas tropicais (Baskin \& Baskin, 1998). Na maioria dos casos, para as espécies arbustivas e arbóreas existe antagonismo entre o tamanho das sementes e o número de sementes por fruto, conforme observou Carvalho et al., (1998).

O melão de São Caetano (Mormodica charantia L.) por ser uma espécie que se destaca pelo seu potencial medicinal caseiro, e por não haver registro de sua exploração na região de Mossoró, RN, bem como estudos relacionados a sua biometria, torna-se necessário a realização de estudos referente a esta espécie, destacando o seu fruto.

Diante do exposto, o presente trabalho teve como objetivo avaliar a biometria dos frutos e do número de sementes por fruto do melão de São Caetano, como subsídio para estudos de comparação de suas características quando submetidos a diferentes ambientes.

\section{MATERIAL E MÉTODOS}

O estudo foi realizado em Mossoró, RN, cujas coordenadas geográficas são: 5'11' S e 37॰20' W com $18 \mathrm{~m}$ de altitude, com uma temperatura média anual em torno de $27,5^{\circ} \mathrm{C}$ e umidade relativa de 68,9\% (Carmo Filho et al., 1991). Segundo classificação climática de Köppen, o clima de Mossoró é do tipo BSwh', ou seja, quente e seco.

Foram coletados a esmo 200 frutos do melão de São Caetano em uma área de vegetação nativa com presença da espécie, localizado dentro do campus da Universidade Federal Rural do SemiÁrido (UFERSA), no município de Mossoró, Estado do Rio Grande do Norte em junho de 2010, e levadas em sacos de papel hermeticamente fechados para o laboratório do Departamento de Ciências Vegetais localizado no setor de fitotecnia, para a medição, pesagem e contagem do número de sementes por

Rev. Bras. PI. Med., Campinas, v.17, n.4, p.505-514, 2015. 
fruto. Para as determinações descritas a seguir foi tomada uma amostra de 200 frutos.

Neste estudo avaliaram-se as seguintes características: a) caracterização morfológica do fruto, sendo determinado o comprimento e o diâmetro, com o auxílio de um paquímetro com precisão de 0,1 milímetros e os resultados expressos em centímetros. O comprimento foi medido da base até o ápice e o diâmetro na linha mediana das sementes; b) peso do fruto expresso em gramas e c) número de sementes por fruto. Para a caracterização morfológica da semente foram avaliados o comprimento e a largura em centímetros de 600 sementes bem desenvolvidas com auxílio de um paquímetro.

As análises descritivas e gráficas foram realizadas utilizando o pacote estatístico (software) $\mathrm{R}$, versão 3.1.1(2014).

\section{RESULTADOS E DISCUSSÃO}

Para determinar e comparar aspectos quantitativos importantes das distribuições dos valores das variáveis comprimento, diâmetro e o peso do fruto, bem como o seu número de sementes, o presente trabalho apoiou-se na literatura biométrica especializada (Spiegel \& Stephens, 2009; Bussab \& Morettin, 2010; Zar, 2010; Claudio \& Stein, 2011; Cecon et al. 2012; Oliveira et al., 2009), e assim, elegeu-se os estimadores estatísticos das variáveis sob estudo, que são as principais medidas de estatística descritiva ou dedutiva, tais como a média aritmética, a mediana, a amplitude total, a variância, o desvio padrão, o erro padrão da média, o coeficiente de variação, o coeficiente de assimetria, o coeficiente de curtose, os quartis, o desvio interquartílico, o coeficiente de correlação de Pearson, bem como a aplicação de técnicas de inferência estatística como os testes de hipóteses ou de significância t e o teste $Z$ a um nível de significância de $5 \%$ de probabilidade, baseado na distribuição t de Student e na distribuição Normal ou Gaussiana respectivamente, na construção de intervalos de confiança com $95 \%$ de probabilidade (Tabelas 1 a 6 e Figuras 1 a 8 ).

Os resultados da análise estatística (Tabela 5) mostram uma baixa amplitude de variação para as variáveis comprimento e diâmetro, bem como um valor bom para os coeficientes de variação, o que mostra um razoável grau de homogeneidade destas características avaliadas, sendo o diâmetro menos disperso do que o comprimento dos frutos. Não existe uma grande semelhança na localização do comprimento e do diâmetro dos frutos, pois as médias 5,51 e 6,88 centímetros, para o comprimento médio e o diâmetro médio, respectivamente, não estão muito próximas. Vale salientar que o cálculo
TABELA 1. Distribuição de frequências referente ao comprimento de frutos de melão de São Caetano (Momordica charantia L.). Mossoró, RN, 2015.

\begin{tabular}{cccc}
\hline $\begin{array}{c}\text { Classes } \\
\text { (Comprimento em cm) }\end{array}$ & $\mathbf{f}_{\mathbf{i}}$ & $\mathbf{X}_{\mathbf{i}}$ & $\boldsymbol{f \%}$ \\
\hline$[3,5---------4,4)$ & 27 & 3,5 & 13,5 \\
{$[4,4--------5,2)$} & 72 & 6,3 & 36,0 \\
{$[5,2--------6,1)$} & 44 & 9,0 & 22,0 \\
{$[6,1--------7,0)$} & 30 & 11,7 & 15,0 \\
{$[7,0--------7,8)$} & 27 & 14,4 & 13,5 \\
Total & 200 & ------ & 100 \\
\hline
\end{tabular}

TABELA 2. Distribuição de frequências referente ao diâmetro de frutos de melão de São Caetano (Momordica charantia L.). Mossoró, RN, 2015.

\begin{tabular}{cccc}
\hline $\begin{array}{c}\text { Classes } \\
\text { (Diâmetro em cm) }\end{array}$ & $\mathbf{f}_{\mathbf{i}}$ & $\mathbf{X}_{\mathbf{i}}$ & $\boldsymbol{f} \%$ \\
\hline$[5,0--------5,8)$ & 25 & 5,4 & 33,0 \\
{$[5,8---------6,5)$} & 51 & 6,1 & 40,5 \\
{$[6,5--------7,3)$} & 56 & 6,9 & 16,5 \\
{$[7,3--------8,0)$} & 52 & 7,7 & 8,0 \\
{$[8,0--------8,8)$} & 16 & 8,4 & 2,0 \\
Total & 200 & ------ & 100 \\
\hline
\end{tabular}

da média não tem que fazer sentido real. Pode-se afirmar entretanto, que os frutos tem um centro de gravidade na distribuição dessas variáveis, o que mostra que o comprimento dos frutos está próximo de 5,51 e o diâmetro em torno de 6,88 centímetros.

A variação relativa das variáveis medidas utilizando-se os coeficientes de variação, neste caso, foi o mais adequado, pois independem da magnitude da variável, bem como de sua unidade de medida, sendo, portanto o procedimento mais correto. Os valores obtidos dos coeficientes de variação (18,08 e 13,16\% para o comprimento e o diâmetro, respectivamente), mostram uma dispersão relativa semelhante ou próxima para as duas características, evidenciando mesmo assim uma menor variabilidade relativa para o diâmetro, mas de uma magnitude da diferença pouco significativa (Ferreira, 2005; Oliveira et al. 2009; Zar, 2010; Fonseca \& Martins, 2012).

Outros resultados obtidos (Tabela 5 ) mostram que as médias e medianas foram muito próximas, indicando um forte grau de simetria que foram 0,23 e -0,01 para comprimento e diâmetro, 
TABELA 3. Distribuição de frequências referente ao peso de frutos de melão de São Caetano (Momordica charantia L.). Mossoró, RN, 2015.

\begin{tabular}{cccc}
\hline $\begin{array}{c}\text { Classes } \\
\text { (Pesos em g) }\end{array}$ & $\mathbf{f}_{\mathbf{i}}$ & $\mathbf{X}_{\mathbf{i}}$ & $\boldsymbol{f} \%$ \\
\hline$[2,2--------4,9)$ & 66 & 3,5 & 33,0 \\
{$[4,9--------7,6)$} & 81 & 6,3 & 40,5 \\
{$[7,6--------10,4)$} & 33 & 9,0 & 16,5 \\
{$[10,4-----13,1)$} & 16 & 11,7 & 8,0 \\
{$[13,1------15,8)$} & 4 & 14,4 & 2,0 \\
Total & 200 & ------- & 100 \\
\hline
\end{tabular}

TABELA 4. Distribuição de frequências referente ao número de sementes por fruto de melão de São Caetano (Momordica charantia L.). Mossoró, RN, 2015.

\begin{tabular}{crrr}
\hline $\begin{array}{c}\text { Classes } \\
\text { (Número de } \\
\text { sementes por fruto) }\end{array}$ & $\mathbf{f}_{\mathrm{i}}$ & $\mathbf{X}_{\mathrm{i}}$ & $\boldsymbol{f} \%$ \\
\hline$[6,0---------11,4)$ & 66 & 8,7 & 16,0 \\
{$[11,4-------16,8)$} & 81 & 14,1 & 33,5 \\
{$[16,8--------22,2)$} & 33 & 19,5 & 28,0 \\
{$[27,6--------33,0)$} & 16 & 24,9 & 21,0 \\
{$[13,1--------15,8)$} & 4 & 30,3 & 1,5 \\
Total & 200 & ------- & 100 \\
\hline
\end{tabular}

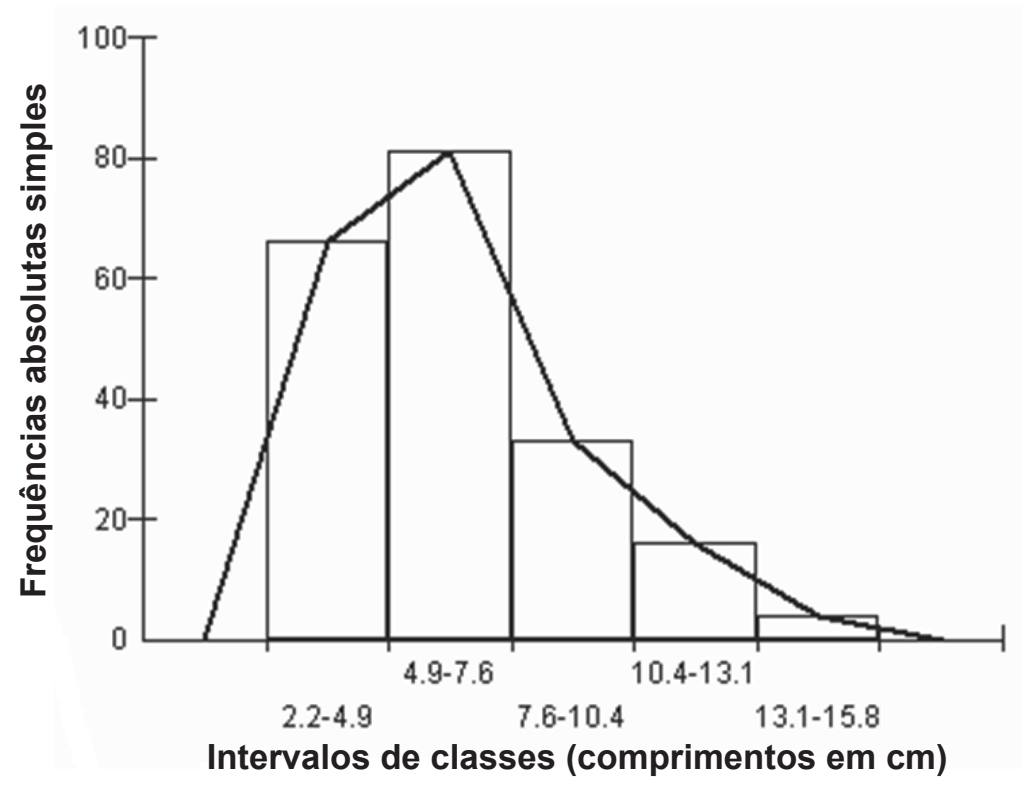

FIGURA 1. Histograma e polígono de freqüências representativos da distribuição do comprimento de frutos do melão de São Caetano (Momordica charantia L.). Mossoró, RN, 2015.

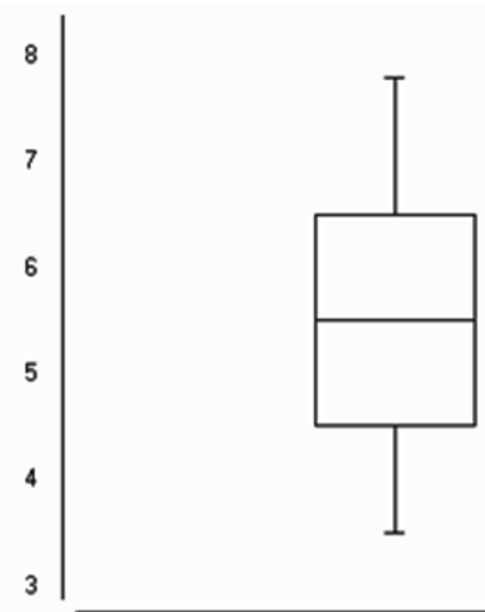

FIGURA 2. Box Plot referente ao comprimento de frutos do melão de São Caetano (Momordica charantia L.). Mossoró, RN, 2015. 


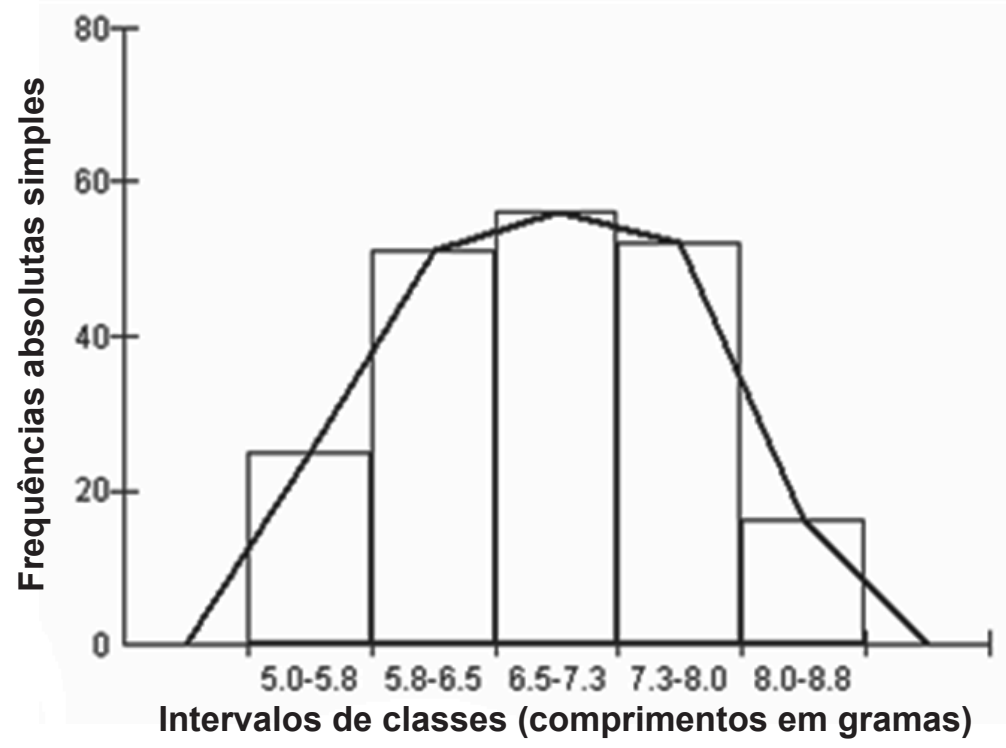

FIGURA 3. Histograma e polígono de freqüências representativos da distribuição do diâmetro de frutos do melão de São Caetano (Momordica charantia L.). Mossoró, RN, 2015.

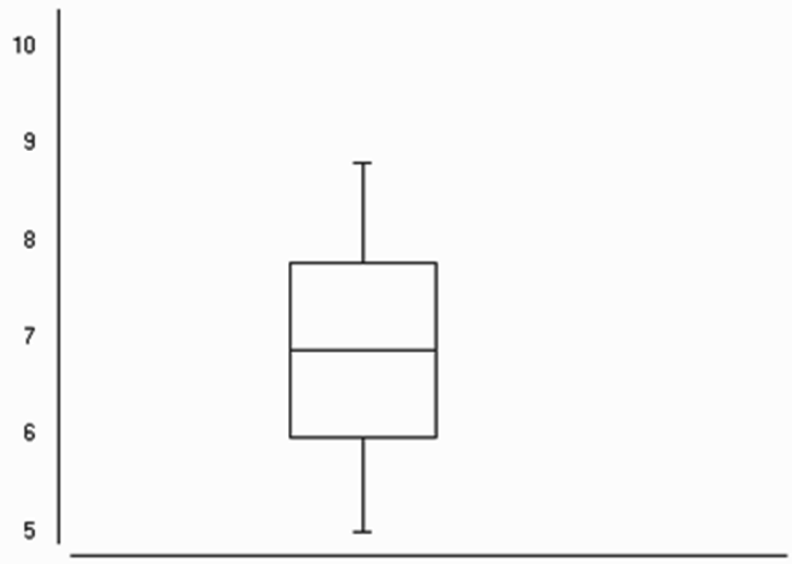

FIGURA 4. Box Plot referente ao diâmetro do fruto do melão de São Caetano (Momordica charantia L.). Mossoró, RN, 2015.

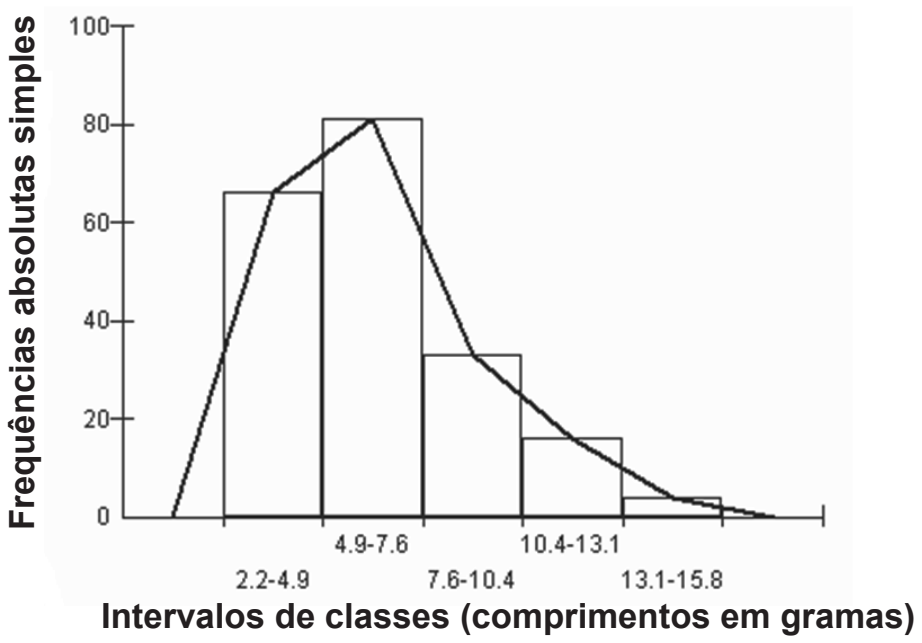

FIGURA 5. Histograma e polígono de freqüências representativos da distribuição do peso do fruto do melão de São Caetano (Momordica charantia L.). Mossoró, RN, 2015. 


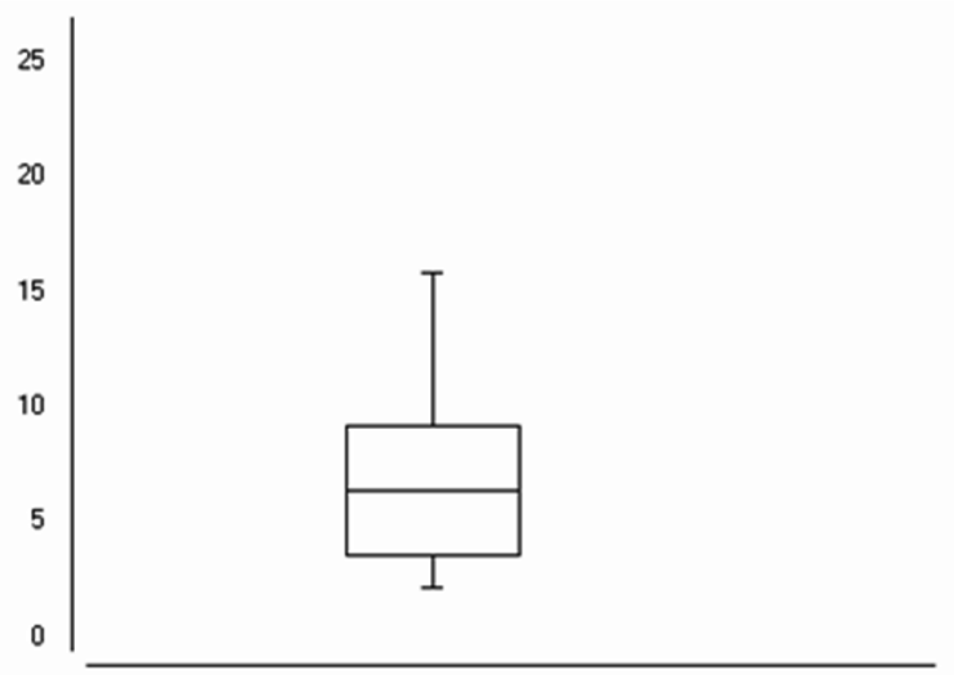

FIGURA 6. Box Plot referente ao peso de sementes de melão de São Caetano (Momordica charantia L.). Mossoró, RN, 2015.

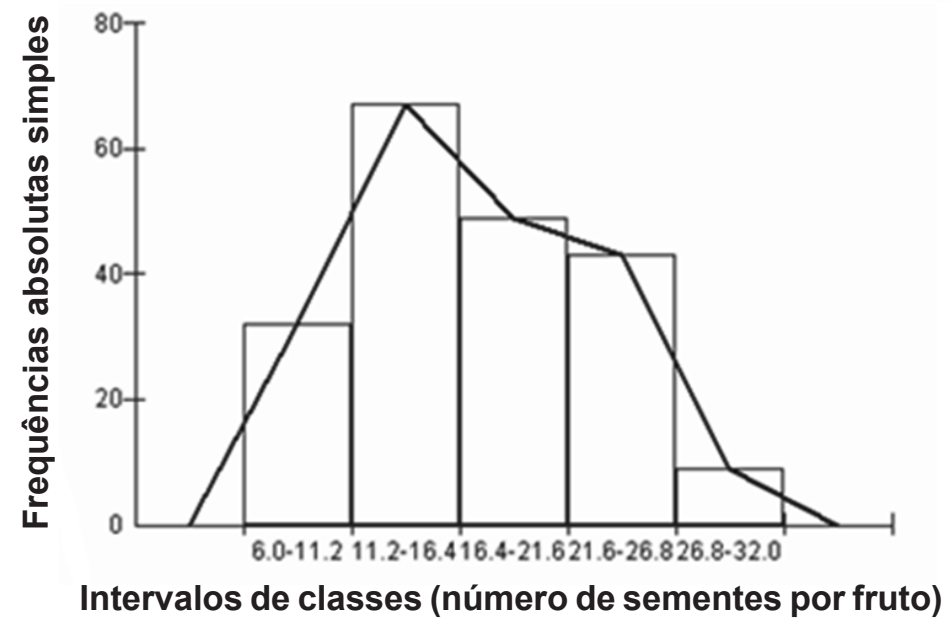

FIGURA 7. Histograma e polígono de freqüências representativos da distribuição do número de sementes por fruto do melão de São Caetano (Momordica charantia L.). Mossoró, RN, 2015.

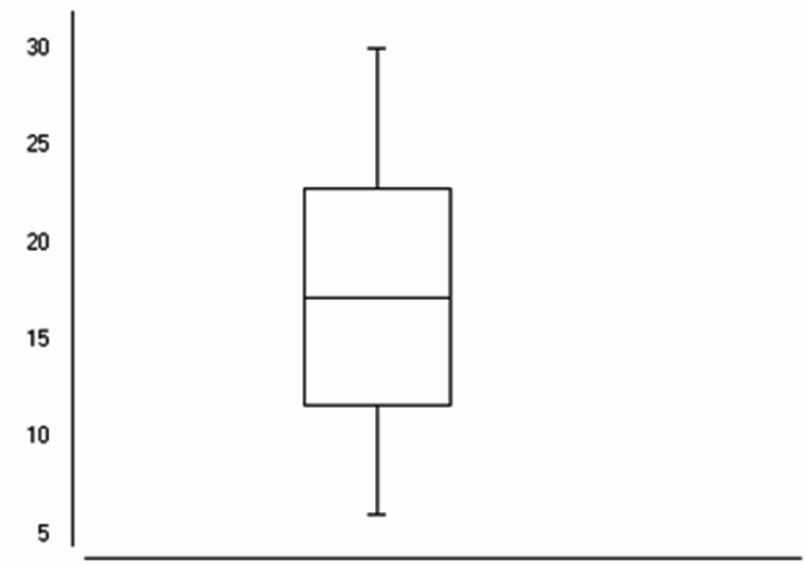

FIGURA 8. Box Plot referente ao número de sementes por fruto do melão de São Caetano (Momordica charantia L.). Mossoró, RN, 2015. 
TABELA 5. Resultados amostrais da análise estatística descritiva e indutiva referente às variáveis comprimento e diâmetro de 200 frutos de melão de São Caetano (Momordica charantia L.). Mossoró, RN, 2015.

\begin{tabular}{|c|c|c|}
\hline Estatística amostral ou estimador & Comprimento & Diâmetro \\
\hline tamanho da Amostra (número de frutos) & 200 & 200 \\
\hline Valor Mínimo $(\mathrm{cm})$ & 3,50 & 5,00 \\
\hline Valor Máximo (cm) & 7,80 & 8,80 \\
\hline Amplitude Total $(\mathrm{cm})$ & 4,30 & 3,80 \\
\hline Média Aritmética (cm) & 5,51 & 6,88 \\
\hline Mediana ou Segundo Quartil (cm) & 5,30 & 6,90 \\
\hline Variância $(\mathrm{cm})^{2}$ & 0,99 & 0,82 \\
\hline Desvio Padrão (cm) & 0,99 & 0,91 \\
\hline Erro Padrão da Média (cm) & 0,07 & 0,06 \\
\hline Coeficiente de Variação (\%) & 18,08 & 13,16 \\
\hline Coeficiente de Assimetria & 0,23 & $-0,01$ \\
\hline Coeficiente de Curtose & $-0,71$ & $-0,77$ \\
\hline Intervalo Interquartílico (IIQ) (cm) & 0,67 & 0,70 \\
\hline Coeficiente de Correlação Linear & $+0,66(66 \%)$ (valor $p$ do teste $t$ de & \\
\hline Simples de Pearson ( $r$ ) & "Student" < 0,01) & \\
\hline Z Teste a $1 \%$ de probabilidade & $78,71^{* *}$ & $107,5^{\star *}$ \\
\hline Intervalo de Confiança a $95 \%$ de Probabilidade $(\mathrm{cm})$ & 5,37 a 5,65 & 6,75 a 7,00 \\
\hline Distribuição Normal & Valor $p=0,13$ & Valor $p=0,15$ \\
\hline \multicolumn{3}{|l|}{ Teste D'Agostino - Pearson } \\
\hline Ajuste de regressão linear simples & \multicolumn{2}{|c|}{$r^{2}$ ajustado $=0,43=43 \%($ valor $p$ do teste $t$ de "Student" $<0,01)$} \\
\hline
\end{tabular}

respectivamente. Já os coeficientes momento de curtose que deram $-0,71$ e $-0,77$, respectivamente, mostraram que tanto o comprimento como o diâmetro tem uma distribuição de frequência mesocúrtica, sendo que a caracterização do grau de assimetria e de curtose de uma distribuição conforme Spiegel \& Stephens (2009), Zar (2010), Fonseca \& Martins (2012), Casella \& Berger (2010) e Andrade \& Ogliari (2010), não pode ser feita olhando apenas para as medidas de posição ou tendência central como é o caso da média e da mediana, mas também através dos coeficientes de assimetria e de curtose, bem como através dos histogramas e polígonos de frequências (Figuras 1 a 3 ).

Com relação aos quantis, o primeiro quartil mostra que $25 \%$ dos menores valores para o comprimento e o diâmetro dos frutos atingem no máximo 5,00 e 6,10 centímetros respectivamente. Já os $25 \%$ maiores comprimentos e diâmetros dos frutos são representados por pelo menos 6,33 e 7,50 centímetros, corroborado por Figueiredo et al. (2007). Neste caso o intervalo interquartílico obtido, que serve para verificar a dispersão dos dados em relação à mediana e desta forma identificar a presença de dados outlier's, foi de 0,67 centímetros para o comprimento e de 0,70 centímetros para o diâmetro do fruto (Tabela 5).

O grau de associação linear simples cujo campo de definição físico varia de $-1 \mathrm{a}+1$, inclusive podendo ser zero ou nulo, entre as variáveis comprimento $(x)$ e diâmetro dos frutos $(y)$ do melão de São Caetano, cuja magnitude é adimensional foi de 0,66 (Tabela 5), evidenciando uma correlação linear simples positiva entre estas características, o qual revela três aspectos importantes, a direção, a forma e a força ou intensidade da associação entre as variáveis, e que foi significativa pelo teste " $t$ " de Student a $1 \%$ de probabilidade, mostrando que quando o valor do comprimento aumenta ou diminui os valores do diâmetro também aumentam ou diminuem numa proporção muito próxima, onde os pares $x$ e y crescem na mesma proporção evidenciando uma distribuição normal bivariada (Ferreira, 2005; Figueiredo et al. 2007; Oliveira et al.

Rev. Bras. PI. Med., Campinas, v.17, n.4, p.505-514, 2015. 
TABELA 6. Resultados amostrais da análise estatística descritiva e indutiva referente às variáveis peso do fruto em gramas e número de sementes por fruto em 200 frutos de melão de São Caetano (Momordica charantia L.). Mossoró, RN, 2015.

\begin{tabular}{|c|c|c|}
\hline Estatística amostral ou estimador & $\begin{array}{c}\text { Peso } \\
\text { (Gramas) }\end{array}$ & $\begin{array}{l}\text { Número de } \\
\text { sementes por fruto }\end{array}$ \\
\hline Tamanho da Amostra (número de frutos) & 200 & 200 \\
\hline Valor Mínimo & 2,17 & 6,00 \\
\hline Valor Máximo & 15,81 & 30,00 \\
\hline Amplitude Total & 13,64 & 24,00 \\
\hline Média Aritmética & 6,38 & 17,23 \\
\hline Mediana ou Segundo Quartil & 6,11 & 17,00 \\
\hline Variância $(g)^{2}$ & 7,79 & 31,26 \\
\hline Desvio Padrão & 2,79 & 5,59 \\
\hline Erro Padrão da Média & 0,19 & 0,39 \\
\hline Coeficiente de Variação (\%) & 43,77 & 32,46 \\
\hline Coeficiente de Assimetria & 0,74 & 0,02 \\
\hline Coeficiente de Curtose & 0,26 & $-0,91$ \\
\hline Intervalo Interquartílico (IIQ) & 1,80 & 4,63 \\
\hline Coeficiente de Correlação Linear Simples de Pearson ( $r$ ) & $\begin{array}{c}+0,26(26 \%)(\text { valor } p \text { do teste } t \text { de } \\
\text { "Student" }>0,05)\end{array}$ & \\
\hline Z Teste a $1 \%$ de probabilidade & $32,30^{* *}$ & $4,56^{* *}$ \\
\hline Intervalo de Confiança a $95 \%$ de Probabilidade (mm) & 5,99 a 6,76 & 16,45 a 18,00 \\
\hline $\begin{array}{l}\text { Distribuição Normal } \\
\text { Teste D’Agostino - Pearson }\end{array}$ & Valor $p=0,15$ & Valor $p=0,10$ \\
\hline Ajuste de regressão linear simples & \multicolumn{2}{|c|}{$r^{2}$ ajustado $=0,07=7 \%($ valor $p$ do teste $t$ de "Student" $>$} \\
\hline
\end{tabular}

2009; Spiegel \& Stephens, 2009; Bussab \& Morettin, 2010; Zar, 2010; Claudio \& Stein, 2011; Cecon et al. 2012; Costa, 2012).

No que diz respeito ao $Z$ teste observouse valores elevados tanto para o comprimento como para o diâmetro do fruto, concluindo-se que os valores médios destas características foram altamente significativos. Verificou-se também que estes valores se ajustaram à distribuição normal de probabilidades. (Tabela 5).

O fruto do melão de São Caetano apresentou peso médio de 6,38 gramas e um número de sementes em torno de 17 (Tabela 6). Observou-se para essas variáveis uma alta amplitude de variação, bem como um alto valor para os coeficientes de variação, o que mostra um baixo grau de homogeneidade dessas características, sendo o número de sementes por fruto menos disperso do que o peso do fruto.

Ainda de acordo com os resultados visualizados na Tabela 6 , as médias e as medianas do peso do fruto e do número de sementes do fruto, indicaram um elevado grau de simetria, que foram 0,74 e 0,02 , respectivamente. Já os coeficientes de curtose que foram 0,26 e $-0,91$, respectivamente, mostraram que tanto o peso do fruto como o número de sementes por fruto tem uma distribuição mesocúrtica. Conforme Spiegel \& Stephens (2009), Bussab \& Morettin (2010), Zar (2010) e Costa (2012), e já mencionado anteriormente, a caracterização do grau de assimetria e de curtose não podem ser feitas utilizando-se apenas medidas de posição ou tendência central, mas também através dos coeficientes de assimetria e curtose, bem como usando-se histograma e polígonos de freqüências (Figuras 5 e 7). O intervalo interquartílico obtido 
para o peso do fruto foi de 1,80 gramas, enquanto que para o numero de sementes por fruto foi igual a 4,63 sementes por fruto (Tabela 6), evidenciando para estas características uma maior dispersão dos dados em relação à mediana, ou seja, ocorrendo uma presença maior de dados Outlier's, principalmente para o número de sementes por fruto.

Com relação ao grau de associação linear simples de Pearson entre as variáveis peso do fruto e número de sementes por fruto, obteve um valor de $+0,26$ o qual não foi significativo pelo teste $t$ de Student (Tabela 6).

Através da aplicação do teste $Z$ observouse significância ao nível de $1 \%$ de probabilidade, para os valores médios do peso do fruto e do número de sementes por fruto. Verificou-se também que estes valores se ajustaram à distribuição normal de probabilidade. (Tabela 6).

De uma maneira geral os resultados das medidas descritivas de localização, variabilidade, assimetria e curtose podem servir de base para futuros estudos de análise descritiva e de inferência estatística, para a comparação de diferentes ambientes, estudos de melhoramento genético vegetal, subsidiar critérios utilizados para o agrupamento de experimentos em análise conjunta, em análise de estabilidade de cultivares, bem como na construção dos chamados componentes de variância (Ferreira, 2005; Figueiredo et al. 2007; Oliveira et al. 2009; Spiegel \& Stephens, 2009; Bussab \& Morettin, 2010; Casella \& Berger, 2010; Zar, 2010; Claudio \& Stein, 2011; Cecon et al. 2012; Costa, 2012).

Conclui-se que o comprimento e o diâmetro dos frutos apresentaram uma baixa amplitude de variação, bem como um bom valor para os coeficientes de variação o que mostrou um elevado grau de homogeneidade destas características avaliadas, sendo o diâmetro menos disperso do que o comprimento;

O peso do fruto e o número de sementes por fruto mostraram uma alta amplitude de variação, e um alto valor para os coeficientes de variação, evidenciando um baixo grau de homogeneidade para estas características, sendo o número de sementes menos disperso do que o peso;

Constatou-se que os dados referentes a todas as características do fruto do melão de São Caetano, avaliados neste trabalho, se ajustaram à distribuição normal de probabilidades.

\section{AGRADECIMENTO}

Ao Grupo de Pesquisa Jitirana para o estudo de espécies espontâneas da caatinga, e a Universidade Federal Rural do Semi-Árido UFERSA - Mossoró, RN, pela infraestrutura para o desenvolvimento dos trabalhos.

\section{REFERÊNCIAS}

ANDRADE, D. F.; OGLIARI, P. J. Estatística para as ciências agrárias e biológicas com noções de experimentação. 3 ed. Florianópolis: Editora da UFSC, 2010. 470 p.

ASSUBAIE, N. F.; EL-GARAWANY, M. M. Evaluation of Some Important Chemical Constituents of Momordica charantia Cultivated in Hofuf. Saudi Arabia Journal of Biological Sciences, v. 4, n.1, p. 628-630. 2004.

BASKIN, C. C.; BASKIN, J. M. Seeds: ecology, biogeography and evolution of dormancy and germination. San Diego: Academic Press 1998. 666 p.

BUSSAB, W. O.; MORETTIN, P. A. Estatística básica. 6. ed. São Paulo: Saraiva, 2010. 540 p.

CARMO FILHO, F.; et al. Dados meteorológicos de Mossoró (janeiro de 1989 a dezembro de 1990). Mossoró: ESAM, FGD, 1991. 110 p. Coleção Mossoroense, Série C, 630.

CARPANEZZI, A. A.; MARQUES, L. C. T. Germinação de sementes de jutaí-açu (Hymenaea courbaril L.) e de jutaí-mirim ( $H$. parvifolia Huber) escarificadas com ácido sulfúrico comercial. Circular Técnica 19. EMBRAPACPATU, Belém. 1981.15p.

CARVALHO, J. E. U.; et al. Características físicas e de germinação de sementes de espécies frutíferas nativas da Amazônia. Boletim de Pesquisa 203. EMBRAPACPATU, Belém. 1998.18p.

CASELLA, G.; BERGER, R. L. Inferência estatística. São Paulo: Editora Cengage Learning. 2010. 612 p.

CECON, P. R.; et al. Métodos estatísticos. Viçosa: Editora UFV. 2012, 229 p.

CLAUDIO L. C.; STEIN, C. E. Estatística descritiva e teoria das probabilidades. 2. ed. Blumenau : Edifurb, 2011. 213 p.

DI STASI, L. C.; HIRUMA-LIMA, C. A. Plantas medicinais na Amazônia e na Mata Atlântica. 2. ed. São Paulo: Editora Universidade Estadual Paulista, 2002. 604 p.

DUBICK, A. M. Historical perspectives on the use of herbal preparations to promote health. Journal of Nutrition, v. 1, n. 116, p.1348-1354.1986.

FENNER, M. Seed ecology. London: Chapman \& Hall, $1993.151 \mathrm{p}$.

FERREIRA, D. F. Estatística básica. Lavras: UFLA, 2005. $625 \mathrm{p}$.

FIGUEIREDO, F.; et al. Estatística descritiva e probabilidades - problemas resolvidos e propostos com aplicações em R. Lisboa: Portugal: Escolar Editora, 2007. 420 p.

FONSECA, J. S.; MARTINS, G. A. Curso de estatística. 6. Ed. 15. reimp. São Paulo: Atlas, 2012. 320 p.

GIRON, L. M.; et al. Ethnobotanical survey of the medicinal flora used by the Caribs of Guatemala. Journal of Ethnopharmacology, v. 34, n. 2 e 3, p.173-187.1991.

GROVER, J. K.; YADAV, S. P. Pharmacological actions and potential uses of Momordica charantia: a review. Journal of Ethnopharmacology, v.1, n. 93, p.123132. 2004.

LANS, C.; BROWN, G. Observations on ethnoveterinary medicines in Trinidad and Tobago. Preventive Veterinary Medicine, v.1, n. 35, p.125-142. 1998.

LIM, T. K. Loofahs, gourds, melons and snake beans. The New Rural Industries. Ed.: K. W. Hyde.

Rev. Bras. PI. Med., Campinas, v.17, n.4, p.505-514, 2015. 
Canberra, Rural Industries Research and Development Corporation : p. 212-218. 1998.

LORENZI, H. Plantas daninhas do Brasil: terrestres, aquáticas, parasitas e tóxicas. 3. ed. Nova Odessa, SP: Instituto Plantarum, 2000. 640 p.

COSTA, G. G. O. Curso de estatística inferencial e probabilidades: teoria e Prática. São Paulo: Editora Atlas, 2012. $370 \mathrm{p}$.

OLIVEIRA, M.S.; et al. Introdução à estatística. Lavras, MG: Editora da Universidade Federal de lavras (UFLA), 2009. 329 p.

R VERSION 3.1.1.Viena, Austria: Foundation for Statistical Computing, 2014. (Software).

RAO, K. V. K.; et al. Plant derived products as a source of cellular growth inhibitory phytochemicals on PC-3M, DU-145 and LNCaP prostate cancer cell lines. Current Science, 87, p. 1585-1588. 2004.

REYES, M. E. C.; et al. Momordica L. In: Plant Resources of South-East Asia: Vegetables. (Ed.: Siemonsma, J. S. and K. Piluek). Wageningen, The Netherlands, Pudoc Scientific Publishers. p. 206-210. 1994.

RIBEIRO, L. F. C.; et al. Ocorrência de um fitoplasma do grupo 16 Srlll associado ao enfezamento em melão de São Caetano (Momordica charantia L.) no Estado de São Paulo. Summa Phytopathol, v. 3, n. 30. 2004.

ROBINSON, R. W.; DECKER - WALTER, D. S. Cucurbits. New York: Cab International, 1997. 226 p. SPIEGEL, M. R.; STEPHENS, L. J. Estatística. 4 ed. Porto Alegre: Bookman, 2009. 597 p.

VINNING, G. Market Compendium of Asian Vegetables. RIRDC Research Paper No. 95/12. Canberra, Rural Industries Research and Development Corporation. 1995. 386 p.

ZAR, J. H. Biostatistical analysis. 5. Ed. New York: Prentice - Hall/Pearson, 2010. 944 p. 